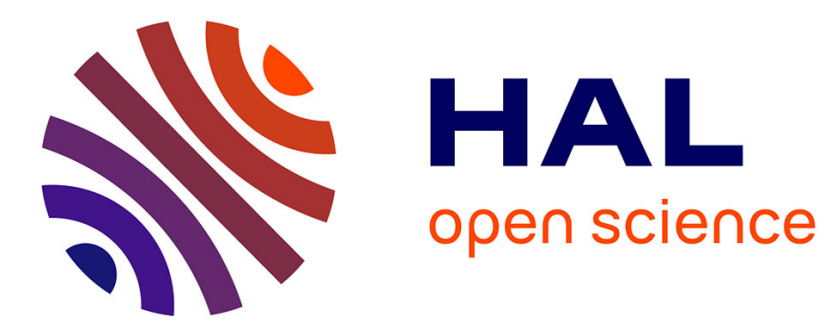

\title{
Collaborative Systems in Crisis Management: A Proposal for a Conceptual Framework
}

Frederick Benaben, Anne-Marie Barthe-Delanoë, Matthieu Lauras, Sébastien Truptil

\section{- To cite this version:}

Frederick Benaben, Anne-Marie Barthe-Delanoë, Matthieu Lauras, Sébastien Truptil. Collaborative Systems in Crisis Management: A Proposal for a Conceptual Framework. 15th Working Conference on Virtual Enterprises (PROVE), Oct 2014, Amsterdam, Netherlands. pp.396-405, 10.1007/978-3662-44745-1_39. hal-01392142

\section{HAL Id: hal-01392142 \\ https://hal.inria.fr/hal-01392142}

Submitted on 4 Nov 2016

HAL is a multi-disciplinary open access archive for the deposit and dissemination of scientific research documents, whether they are published or not. The documents may come from teaching and research institutions in France or abroad, or from public or private research centers.
L'archive ouverte pluridisciplinaire $\mathbf{H A L}$, est destinée au dépôt et à la diffusion de documents scientifiques de niveau recherche, publiés ou non, émanant des établissements d'enseignement et de recherche français ou étrangers, des laboratoires publics ou privés.

\section{(c)(1)}

Distributed under a Creative Commons Attribution| 4.0 International License 


\title{
Collaborative Systems in Crisis Management: A Proposal for a Conceptual Framework
}

\author{
Frédérick Bénaben, Anne-Marie Barthe-Delanoë, \\ Matthieu Lauras and Sébastien Truptil \\ Mines Albi - University of Toulouse, Campus Jarlard, Route de Teillet 81000 Albi - France \\ \{frederick.benaben, anne-marie.barthe, matthieu.lauras, sebastien.truptil\}@ mines-albi.fr
}

\begin{abstract}
This article aims at presenting a three-dimensional framework dedicated to structure the domain of crisis management. The approach is based on a formalized vision of crisis (the danger / risk / consequence chain) that is used to define the what, when and where of crisis management. These three basic questions allow describing the management, time (life cycle) and localization dimensions of crisis management. The obtained framework is also compared with a simple vision of collaborative networks (the information / function / process interweaving) to identify some requirements and expectations for collaborative networks in crisis management context. Furthermore, this very "static" framework is also exposed in a "dynamic" manner to support agility of collaborative network in crisis management.
\end{abstract}

Keywords: Framework, Crisis management, Collaborative network, Conceptualization.

\section{Introduction}

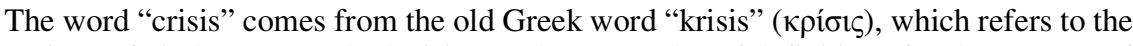
notions of "judgment" and "decision". There are a lot of definitions for the concept of crisis $[1,2]$. These definitions can be studied to suggest the following one: a state of a system, which reveals instability and discontinuity and which requires a specific treatment to deal with the unwanted consequences and to obtain a new acceptable state of the considered system.

Crisis management directly refers to the mentioned treatment in the previous definition and can be defined as: the governance mode that is applied to bring the system from the crisis state to a (potentially new) stable and acceptable state.

Anyway, crisis management is a very complex domain with a lot of constraints, points of view and heterogeneous aspects to take into account. Consequently, it is very difficult to get a global overview of such a domain. This article is mainly dedicated to present a framework for crisis management. The initial questions are the followings: how to define such a framework? What should be the significant elements to take into account? What are the points of view and dimensions that should be considered to structure this framework?

Obviously, the framework presented in this article does not claim nor to be the optimal one, neither to be able to fit absolutely all cases of crisis situations. However, 
the overall objective is to be covering of the crisis management field as much as possible and after all also to be partially usable (some crisis situations might be characterized only according to one or two of the proposed dimensions). The proposed framework, not so far from FTA (Fault Tree Analysis) principles [3], is based on the following concepts chain: Danger / Risk / Consequence. Furthermore, Danger, Risk and Consequences may be considered as causal sources (in a waterfall structure) that must be formalized as models to help decisions makers (close to models/decision graphs).

This article is structured according to the following sections. In section 2, an overall vision of crisis is presented in order to initiate and legitimate the framework description process. In section 3, the three-dimensional crisis management framework is presented. In section 4 , the consequences of such a framework for collaborative network are studied. In section 5, elements regarding dynamicity of crisis management are also introduced (especially to deal with the question of agility). Finally, a conclusion describes some perspectives and ways to exploit this framework.

\section{Main Concepts of Crisis Management}

\subsection{Crisis primary modeling}

Schematically, and in a "reverse" mode, crisis may be seen as a set of negative facts (presented as consequence in the following picture). Each of these negative facts is due to one (or several) event(s) that trigger(s) one (or several) risk(s). This (or these) risk(s) occur(s) because the considered area/system is concerned by one (or several) danger(s) that affect(s) one (or several) stake(s).

Figure 1 presents this danger (and stake) / risk (and event) / consequence chain:

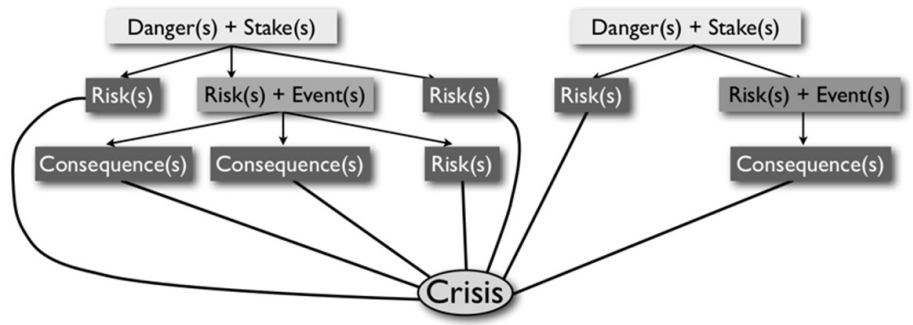

Fig. 1. Danger/Risk/Consequence chain for crisis description

In this schema, danger is a characteristic of the considered system while risk is a potential manifestation of this danger regarding some concerned stakes. If one risk might occur it would be due to some events. The following picture illustrates this: 

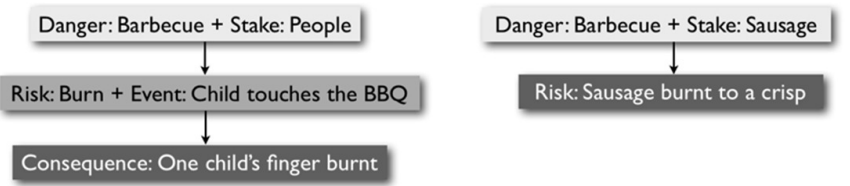

Fig. 2. A first illustration of the Danger/Risk/Consequence chain for crisis description.

Cooking with a Barbecue is a danger for two main stakes: people around (the risk is that they could be burnt) and the meat (the risk is that it could be badly cooked). The next figure also illustrates this general schema by providing a simple vision of the Fukushima crisis:

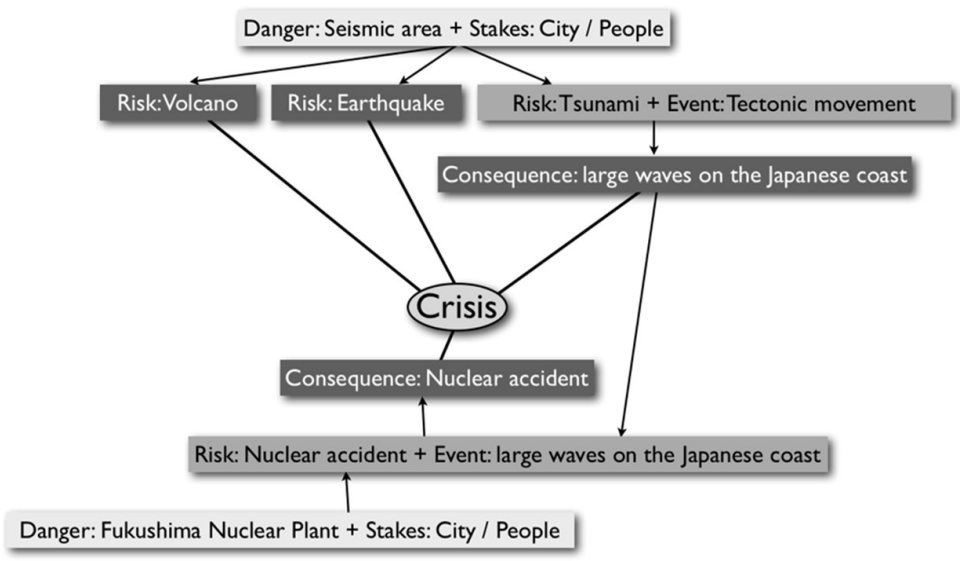

Fig. 3. A second illustration of the Danger/Risk/Consequence chain for crisis description

One main element of this illustration is the fact that event might be due to a consequence or even a risk: a consequence is an event by nature and the appearance of a new risk is also an event. One danger in Japan is that the local area is a seismic area that can affect stakes (such as people, goods, city, natural sites, etc.).

The risks are volcanic eruptions, earthquakes and tsunamis. Concerning the Fukushima crisis, the tsunami risk occurs due to a specific event (tectonic movement).

The consequence was large waves hitting the Japanese coast. This consequence was also an event that triggers the risk of nuclear accident on the Fukushima Daiichi nuclear plant.

Obviously, the previous model could be really more detailed considering the failure of the cooling process of the nuclear reactor as a consequence (and also an event), considering also the risks of fusion, explosion, etc. That shows how this general principle might be considered according to different granularity levels (in a fractal mechanism). 
It is also to be mentioned that risk is often considered as a probability. This is compliant with the previous model: risks are presented in the model only if the probability of their occurrence is significant (i.e. not too low). Besides, risks are also often evaluated through the probability $x$ gravity matrix. This is also compliant with the presented model as far as gravity is assessed thanks to stakes.

\subsection{Consequences of such a model for crisis management}

Considering the previous simple model for crisis and also the definition of crisis management (i.e. the governance mode), it appears that crisis management requires dealing with risks and consequences. The main goal is to prevent existing risks and to treat existing consequences. Existing risks might have been identified before the crisis itself or might have appeared due to some events during the crisis. Similarly, consequences might be the concretization of risks existing before the crisis, or appeared during the crisis.

These considerations will be used in the remainder of this article to refine a very classical three-dimensional approach: crisis management may be considered according to: what? (What are the management types/levels to consider?), when? (What are the different steps/phases/times of crisis management?), and where? (What are the concerned physical areas/perimeters?).

\section{A Framework Proposal}

\subsection{The management dimension}

The main statement for this first dimension of crisis management is that crisis management requires:

- Decisions to deal with the objectives to reach (mainly risks to prevent and consequences to treat).

- Actions to perform risk prevention or consequence treatment according to decisions.

- Resources to support actions.

Consequently, the management dimension can be considered according to standards from industrial world [4], which describe three abstraction levels for processes cartography: decisional, operational and support. Nevertheless, this structure might be questionable as far as crisis management, as a very critical context, could be slow down by this formal structure. However, it is also noticeable that a lot of organizations (even military ones) are nowadays using this structuration levels to organize their management.

The management dimension of the framework includes three levels:

1. Decisional level: dealing with strategy and choices to make. This dimension embeds the classical "operational" (different from the next "operational" level of point 2), "tactical" and "strategic" horizons of decision-makers. 
2. Operational (or Realization) level: dealing with concrete actions dedicated to prevent a risk or to treat a consequence.

3. Support level: dealing with resource management, supply chain and all the second order processes.

\subsection{The time dimension}

According to the Danger/Risk/Consequence chain and the main objectives (risk prevention and consequence treatment), crisis management includes, on a given system (area, perimeter, world, etc.):

1. Before the beginning of any crisis: (i) Listing all the risks due to the dangers inherent in the consider system and define preventive actions (actions that prevent the risk occurrence) and curative actions (actions which deal with its consequences if it occurs), (ii) applying the defined preventive actions while there is no crisis (to prevent any crisis).

2. If a crisis occurs: (i) Applying the defined curative actions (to deal with the actual problems) and still preventive actions (to try to prevent any aggravation of the situation), (ii) and defining on-the-fly new actions adapted to potentially emerging unknown risks or consequences.

This is very compliant with the classical phases of crisis managements as described in [5-7]:

1. Prevention (improving the system vulnerability): this phase is to be linked with the previous point (1.i).

2. Preparation (organizing the system in case of expected negative events): linked with point (1.ii).

3. Response (steering of the response system): linked with points (2.i) and (2.ii).

4. Recovery (research for a stable state and capitalization): this phase is complementary to the previous ones and concerns the (often very long) time required to bring the system into a satisfying state (on various points of view such as political, economical, social, etc.).

\subsection{The localization dimension}

This last dimension is more obvious: there are crisis site(s) (on the field where the risks and consequences might be localized) and the crisis cell(s). Crisis site is a sub-part of the world impacted by the crisis situation (i.e. the geographical perimeter containing people, goods, or any other staked affected by the crisis). Crisis cell is the command center where is performed the "high level/granularity" crisis management.

The crisis cell may be distributed horizontally (for geographical reasons) or vertically (for hierarchical reasons). Obviously, operational and support processes concern the crisis site $(s)$ but a lot of the decisions (not all the decisions but, depending 
on the considered crisis, most of them) are taken in crisis cell(s) (including decisions regarding operational or support actions).

Consequently, these two crisis management poles (crisis cell and crisis site), even if potentially divided into several sub-poles (multi-sites or dedicated cells) are connected with each other: instructions are "going down" from the crisis cell( $(s)$ while reports are "going up" from the crisis site $(s)$. Therefore, even if the localization dimension might be considered as a continuous one, it can definitely be discretized according to the three following levels:

1. The level of crisis cell(s), which concerns actions and exchanges inside a crisis cell or between crisis cells.

2. The level of interaction between crisis cells and crisis sites, which concerns the exchange modes between the crisis cells and the crisis sites.

3. The level of crisis site(s), which concerns actions and exchanges between partners on the crisis field.

\subsection{Graphical representation of the proposal of a crisis management framework}

The following picture presents a graphical vision of this framework:

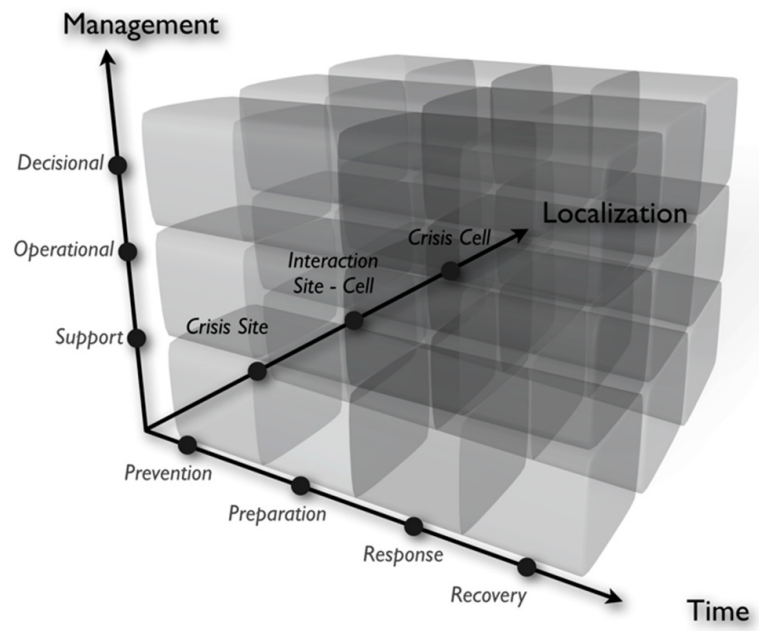

Fig. 4. A three-dimensional framework for crisis management 


\section{The Crisis Management Framework and Collaborative Networks}

The ability to define and set an efficient collaborative network, in the context of crisis management, is one of the key factors of success to help the stakeholders to solve (or at least reduce) the crisis situation [8]. Mainly, collaborative networks, established through the ISs of the collaborative partners, are in charge of three main functions [9]:

- Information management: Based on data storage, transformation and exchange but also knowledge extraction from data.

- Function sharing: Based on identification and invocation of service, software and application including interfaces for human tasks.

- Process orchestration: Based on workflow execution and monitoring.

This simple vision of collaborative networks allows projecting this model of collaborative networks into the crisis management framework in order to extract requirements and expectations for collaborative networks in crisis management context.

By considering the Information / Functions / Processes vision of collaborative networks in the three-dimensional framework of crisis management, it is feasible to identify a set of specific requirements. The following table presents some of these requirements:

Table 1. Collaborative networks requirements extracted from the framework.

\begin{tabular}{|c|c|c|}
\hline Dimensions & Levels & $\begin{array}{c}\text { Requirements for Crisis Management collaborative } \\
\text { networks }\end{array}$ \\
\hline \multirow[t]{2}{*}{ Management } & Decisional & Appropriate circulation and movement of data \\
\hline & $\begin{array}{l}\text { Operational } \\
\text { Support }\end{array}$ & $\begin{array}{l}\text { Orchestration of processes must be relevant } \\
\text { Functions must be available (depending on resources) }\end{array}$ \\
\hline \multirow[t]{3}{*}{ Time } & $\begin{array}{l}\text { Prevention } \\
\text { Preparation }\end{array}$ & $\begin{array}{l}\text { N/A } \\
\text { Configuration: identification of functions and } \\
\text { information (mainly as inputs and outputs of functions) } \\
\text { + partial definition of processes (patterns and plans) }\end{array}$ \\
\hline & Response & $\begin{array}{l}\text { Run-Time: final definition of processes depending on } \\
\text { the specificities of the considered crisis and non- } \\
\text { functional requirements (availability, reliability, etc.) }\end{array}$ \\
\hline & Recovery & Capitalization and continual improvement \\
\hline \multirow[t]{3}{*}{ Localization } & Crisis site(s) & $\begin{array}{l}\text { Multi-devices and material requirement (robustness, } \\
\text { MMI, etc.) }\end{array}$ \\
\hline & $\begin{array}{l}\text { Interaction } \\
\text { Site-Cell }\end{array}$ & Network and telecom efficiency \\
\hline & Crisis cell(s) & Interoperability and integration with existing tools \\
\hline
\end{tabular}

These requirements show that the establishment of a relevant collaborative network in crisis management is dependent on the localization of the specific situation into the 
crisis management framework. For instance, the following cases show how requirements may be extracted from table 1 according to the specificities of the considered crisis situation:

- In the case of the collaborative network of decision makers in the crisis cell in charge of the strategic aspects, it is required that (i) information could circulate easily (especially on an organizational point of view, i.e. actors agree on sharing the knowledge they collect from the field), (ii) the collaborative behavior should be well defined in order to orchestrate the collaborative situation (according to the situation and expected performances) and (iii) partners IS should be interoperable and efficiently connected.

- In the case of preparing actors to work altogether and deploy their operational competencies during training sessions of crisis situation (through exercise for example), it is required that the collaborative network provides (i) clear and identified individual capabilities of actors, (ii) availability of these capabilities and the associated resources and (iii) patterns or schemas of processes that can be tested to demonstrate how some elementary objectives could be achieved by using the available capabilities.

\section{Dynamic Aspect of Crisis Management within the Framework}

Regarding the previously presented framework, it is obvious that crisis management should be considered as covering several (and potentially all) areas of the 3D cube. Resources and stakeholders should be evaluated and trained during preparation phase, the crisis should be driven according to the decisional, operational and support levels, etc. Consequently, crisis management must move inside the framework (in position, in shape and in size), just like a protean structure inside the 3D cube. This is a way to show how agility of crisis management can be represented on a tangible and physical point of view.

Agility is a crucial concept in a collaborative situation such as crisis management. [10] draws the line between this concept and reactivity, flexibility and adaptability. There are four main aspects to this vision: the system must be able to change its structure (flexibility) according to a relevant understanding of the situation (analysis) and its requirements (efficiency) and this should be done in a hurry (reactiveness). In the context of this article, these four facets of agility have also been considered according to two orders: first order represents the main components of agility while second order concerns the features of these main components. Consequently, agility has been defined, on first order, as the capacity of a system to (i) detect any (potentially unexpected) situation that requires the system to change and (ii) adapt its global structure/behaviour to that situation. Regarding second order, two other attributes may be considered: first, the dynamicity of agility might be crucial (performing detection and adaptation too slowly may disrupt agility) and secondly, the relevance of the detection and adaptation may also be critical (wrong detection and adaptation could be 
fatal for the significance of agility). Consequently, this vision may be simply and roughly formulated as:

$$
\text { Agility }=(\text { Detection }+ \text { Adaptation }) \times(\text { Reactiveness }+ \text { Efficiency }) .
$$

Such a formula [11], although not scientific at all, is a structuring scheme that allows the study of agility to be partitioned according to these three properties. Finally, detection and adaptation may be considered as the main attributes of agility while reactiveness and efficiency are the attributes of detection and adaptation (second order).

Based on this definition, agility in crisis management may be considered as the ability of the treatment collaborative network to detect any change (i.e. the next relevant position inside the framework) and to adapt the management (i.e. to make the management move to that next position). Considering also the danger / risk / consequence chain (including the fact that risks and consequences are treated through response processes and activities), this vision of agility could also include the necessity to detect:

1. If the crisis situation (or the perception of the situation) has changed (new risk or new consequence).

2. If the crisis situation is still the same but the collaborative network has changed (new resources, unavailability of a partner, etc.) that is to say activities or processes are not available any more or could be improved.

3. If the crisis situation and the collaborative network are unchanged but an activity or a process did not perform efficiently.

The presented crisis management framework and the danger / risk / consequence chain finally allow to refine the concept of agility into the three previous cases that significantly reduce the issue of agility management in crisis situation.

\section{Conclusion}

The presented framework might be considered as a formalizing reference table dedicated to support the understanding of crisis management (or any correlated concept). The main uses may be the following: connecting research works that belong to the same location in the framework, identifying scientific or technical needs for a crisis management support system (potentially IS) according to the location in the framework.

This framework is compliant with the danger / risk / consequence chain that also help to formalize the knowledge in crisis contexts. The next promising exploitation of these guidelines for knowledge management in crisis managements is the design of knowledge bases and deduction rules to manage data and information coming from the crisis situation, in order to deal with the crisis response and the agility of that response. Besides, the question of granularity levels in the various dimensions of the framework is also a promising issue: scale up / scale down for users, aggregation and split of information in the decision frame, etc. 
Acknowledgments The presented research works have been funded by (i) the French Research Agency (projects ISyCri: Grant ANR-06-SECU-006 and SocEDA: Grant ANR-10-SEGI-013) (ii) the European Commission (project PLAY: Grant FP7-258659) and (iii) the French general direction of competitiveness of industry and services (project OpenPaaS: Grant DGCIS/2012/OpenPaaS). The authors would like to thank the project partners for their advice and comments.

\section{References}

1. Tomasini, R., Van Wassenhove, L.N.: Logistics response in the 2002 food crisis in Southern Africa. INSEAD Case. (2004).

2. Devlin, E.S.: Crisis Management Planning and Execution. CRC Press (2006).

3. Vesely, W.E., Goldberg, F.F., Roberts, N.H., Haasl, D.F., more, \& 1: Fault Tree Handbook. Office of Nuclear Regulatory Research.

4. ISO: Norme européenne NF EN ISO 9001 version 2000, système de management de la qualité - Exigences, http://www.boutique.afnor.org/norme/nf-en-iso9001/systemes-de-management-de-la-qualite-exigences/article/702508/fa145966, (2000).

5. Beamon, B., Kotleba, S.: Inventory modelling for complex emergencies in humanitarian relief operations. International Journal of Logistics: Research and Applications. 9, 1-18 (2006).

6. Altay, N., Green III, W.G.: Abstract Interfaces with Other Disciplines OR/MS research in disaster operations management. Elsevier (2003).

7. Van Wassenhove, L.N.: Humanitarian aid logistics: supply chain management in high gear. J Oper Res Soc. 57, 475-489 (2005).

8. Noran, O.: Towards a Collaborative Network Paradigm for Emergency Services. In: Camarinha-Matos, L.M., Pereira-Klen, A., and Afsarmanesh, H. (eds.) Adaptation and Value Creating Collaborative Networks. pp. 477-485. Springer Berlin Heidelberg (2011).

9. Morley, C., Hugues, J., Leblanc, B., Hugues, O.: Processus métiers et systèmes d'information : évaluation, modélisation, mise en oeuvre. Dunod, Paris (2007).

10. Kidd P.T.: Agile manufacturing: forging new frontiers. Addison-Wesley. London (1994).

11. Barthe-Delanoë, A.-M., Truptil, S., Bénaben, F., Pingaud, H.: Event-driven agility of interoperability during the Run-time of collaborative processes. Decision Support Systems. 59, 171-179 (2014). 